\title{
Article \\ Improving MACD Technical Analysis by Optimizing Parameters and Modifying Trading Rules: Evidence from the Japanese Nikkei 225 Futures Market
}

\author{
Byung-Kook Kang
}

check for

updates

Citation: Kang, Byung-Kook. 2021. Improving MACD Technical Analysis by Optimizing Parameters and

Modifying Trading Rules: Evidence from the Japanese Nikkei 225 Futures Market. Journal of Risk and Financial Management 14: 37. https://doi.org/ 10.3390/jrfm14010037

Received: 21 December 2020 Accepted: 12 January 2021 Published: 16 January 2021

Publisher's Note: MDPI stays neutral with regard to jurisdictional clai$\mathrm{ms}$ in published maps and institutional affiliations.

Copyright: (C) 2021 by the author. Licensee MDPI, Basel, Switzerland. This article is an open access article distributed under the terms and conditions of the Creative Commons Attribution (CC BY) license (https:// creativecommons.org/licenses/by/ $4.0 /)$.
Department of Business Administration, Nanzan University, Aichi 466-8673, Japan; kangbk@nanzan-u.ac.jp

\begin{abstract}
Much research has examined performance or market efficiency by using the moving average convergence divergence (MACD) technical analysis tool. However, most tests fail to verify efficiency with the traditional parameter settings of 12,26, and 9 days. This study confirms that applying the traditional model to Japan's Nikkei 225 futures prices produces negative performance over the period of 2011-2019. Yet, it also finds that the MACD tool can earn significant positive returns when it uses optimized parameter values. This suggests that the Japanese market is not weak-form efficient in the sense that futures prices do not reflect all public information. Hence, the three parameters values of the MACD tool should be optimized for each market and this should take precedence over finding other strategies to reduce false trade signals. This study also tests which models are able to improve profitability by applying additional criteria to avoid false trade signals. From simulations using 19,456 different MACD models, we find that the number of models with improved performance resulting from these strategies is far greater for models with optimized parameter values than for models with non-optimized values. This approach has not been discussed in the existing literature.
\end{abstract}

Keywords: MACD; technical analysis; trading simulation; buy-and-hold strategy; market efficiency; Nikkei 225 futures

\section{Introduction}

MACD (Moving Average Convergence Divergence) is one of the most popular momentum indicators used in the technical analysis of the prices of stocks and other tradeable assets. It consists of three parameters to define three time-periods: two parameters are for the calculation of the MACD series which is the difference between the 'short-term' and 'long-term' exponential moving averages (EMA) of the price series; the other is for the 'Signal' of the series which is an EMA of the MACD. All the series are calculated from historical price data, most often using daily closing prices, and illustrated as a "MACD line" and a "Signal line" on a graphic chart of the indicator. In terms of signal generation, it is common to interpret it as follows: 'buy' when the MACD line crosses up through the Signal line and 'sell' when it crosses down though the Signal line. This trading rule is called a "signal line crossover" and the buy/sell signal is considered to be a primary cue provided by the indicator, although the actual ways investors use the MACD model to trade are diverse.

The most commonly used parameter values are 12, 26, and 9 days, and these values are usually represented in the form MACD $(12,26,9)$. However, the $(12,26,9)$ format is neither a formal standard nor a combination recommended by Appel (1979) who developed the MACD. It is said that Appel originally suggested two different settings on a daily chart: $(8,17,9)$ for buy signals and $(12,25,9)$ for sell signals. Murphy $(1999$, p. 253$)$ later mentioned these two different setting values of Appel and added: "Appel originally recommended one set of numbers for buy signals and another for sell signals. Most traders, however, utilize the default values of 12,26 , and 9 in all instances". In fact, each element of $(12,26,9)$ 
represented - in those times when the work week consisted of 6 days, not 5 days -2 trading weeks, 1 trading month, and one and a half trading weeks, respectively. However, all signals generated by the MACD indicator depend on the three parameter values. Therefore, other values can be substituted according to one's trading style and goals in a way to change the sensitivity of the signal generation process.

Nonetheless, many academic researchers have tested the effectiveness of the MACD approach or used it to measure market efficiency. However, quite a few of these evaluations failed to verify efficiency based on trading results obtained with its three traditional parameter settings of 12,26, and 9 days. They focused their attention on testing whether applying technical analysis tools such as the MACD indicator to financial markets can produce better returns than non-technical buy-and-hold strategies or the risk-free interest rate. Hence, little attention has been given to explaining the optimality of the MACD's traditional parameter value settings. Some researchers utilized different parameter combinations, but they also did not provide any rationale for their values, except for vague words such as, 'because it is most commonly used'. This suggests that if they had considered other values, they may have reached very different conclusions. So there is room to improve the existing approach for tests of market efficiency using the MACD.

On the other hand, the attention of practitioners who utilize the MACD indicator is focused on improving its profitability. Hence, they seek optimal parameter values to obtain the best result. However, it is not easy to test different parameter values because there are too many different potential combinations. Broadly speaking, the main reason to persist in using common parameter values is the momentum of tradition. Meanwhile, when the predictive power of the MACD $(12,26,9)$ model degrades, they question its trade signals and try additional trading strategy criteria to modify these degraded trade signals. In fact, one approach to reduce false trade signals is changing the parameter settings of the MACD to control directly the frequency of signal generation. Another approach is using additional trading strategy criteria to modify indirectly the trade signals produced by the trading rule. However, additional strategies are often based on individual experience and intuition with no consistency. Here arises some simple questions, "Do these supplemental trading strategies make it possible to improve profitability by reducing false trade signals, without changing the traditional parameter values? Or, should the traditional parameters of the MACD model be changed to reduce false trade signals?

From this point of view, the goal of this research is to examine the validity of the following three points:

(1) Whether the application of the traditional MACD model to investing in the Japanese stock market produces genuine profits.

(2) Whether substituting more-optimized, better-fitted parameter values for the traditional ones can deliver higher returns than the traditional model.

(3) Whether applying additional strategies to avoid false trade signals to the models with optimized parameter values improves profitability. And, to be more specific:

- Whether a systematic trading strategy adapted to the models with better-optimized parameter values is able to produce significantly higher returns compared to the traditional model and a non-technical buy-and-hold strategy.

- Whether the effect of applying a systematic trading strategy can be an improvement, even for models with non-optimized parameter values.

There are many published papers using the MACD model. However, little attention has been given to the third point mentioned above (especially to the last sub-point). In this respect, this research is a comparative analysis of the effects of applying additional strategies to the optimized parameter settings and non-optimized settings. Several useful findings and suggestions arise from this research.

The remainder of the research is structured as follows: Section 2 reviews the existing literature related to this research. Section 3 briefly explains the MACD momentum indicator and the limitations caused by false signal generation. Section 4 details the methodology employed in this study. Section 5 presents empirical results on the aforementioned three 
points and comments on them. Section 6 provides concluding remarks with discussion of the implications of the research.

\section{Literature Review}

Many academic researchers adopted the traditional parameter values to test the effectiveness of the MACD approach and measure market efficiency based on the efficient market hypothesis (EMH) of Fama (1970). Chong and Ng (2008) examined the MACD model and another technical analysis tool, the Relative Strength Index (RSI) to see if these trading rules are profitable. Using 60 years of data (1935-1994) for the London Stock Exchange FT30 index, they found that the two trading tools can generate higher returns than a buy-and-hold strategy in the market. The "buy-and-hold" strategy was applied as a benchmark to test the effectiveness of both the MACD and the RSI, which focus on 10-day returns following a buy or sell signal while then ignoring all other transaction signals over these 10 days. In terms of the MACD, they adopted an MACD $(12,26,0)$ model which follows a "zero crossover" trading rule (see Section 3.2 for the details). The reason for adopting this form of the MACD $(12,26,0)$ model was simply because "12- and 26-day are the most commonly used", as quoted by Murphy (1999).

Chong et al. (2014) later examined whether the MACD model and RSI can generally generate excess returns for the stock markets of five other OECD countries (Italy, Canada, Germany, United States and Japan). They applied MACD $(12,26,0), \operatorname{MACD}(12,26,9)$ and MACD $(8,17,9)$ models to market data over 27 years (1976-2002). Their findings were: (1) the MACD $(12,26,0)$ model outperforms a buy-and-hold strategy in the Italian (Milan Comit General) and Canadian (S\&P/TSX Composite Index) stock markets; (2) using the traditional MACD $(12,26,9)$ model led to significant negative returns for the German (DAX 30) stock market and the model had no predictive power for the other countries' markets; and, (3) the returns of the MACD $(8,17,9)$ model—which was introduced by Appel-were significantly negative in the Italian and German markets while it had no predictive power for the other markets. Based on these findings, they concluded that the MACD $(12,26,0)$, $\operatorname{MACD}(12,26,9)$, and $\operatorname{MACD}(8,17,9)$ trading rules are "not robust to the choice of market". But what we should not overlook here is that while the MACD $(12,26,0)$ trading rule outperformed the buy-and-hold strategy in the Italian market, the MACD $(12,26,9)$ model did not show profit potential in the same market. This is strong evidence that suggests that the profitability of the MACD approach will depend on its parameter value settings. To add a remark in passing for the reason why they tried the $\operatorname{MACD}(8,17,9)$ model, it was just because of the following claim that, "it can produce more reliable buy signals" in Pring (2002).

Nor and Wickremasinghe (2014) investigated the profitability of the MACD $(12,26,9)$ model by using a relatively recent data (1996 to mid-2014) for the Australian All Ordinaries Index (XOA). They compared the returns of the MACD $(12,26,9)$ trading rule with 10-day returns for a buy-and-hold strategy using the same approach as Chong and $\mathrm{Ng}$ (2008) and Chong et al. (2014). They found that the traditional MACD model generally performs poorly in the market but that the RSI model showed some profit potential. So, they concluded that overall "the Australian stock market is not weak-form efficient". This brings up the question, "Why is the traditional $(12,26,9)$ model the sole determinant of the profitability of all MACD models and market efficiency"? There is no compelling reason to always use the $(12,26,9)$ parameter settings.

Hejase et al. (2017) have also applied the traditional MACD $(12,26,9)$ model to the stock prices of six Lebanese banks and a real estate company to determine if the MACD tool is able to deliver higher profits to Lebanese stock traders. What is interesting is that, in order to avoid false signals after filtering the empirical results over 10 years of data (20042014), they tested three trading strategies different from the typical 'signal line crossover' trading rule of the MACD model. The first one is to execute a 'buy (sell)' transaction only when three 'buy (sell)' signals are generated on three consecutive days. The second is to execute a 'buy (sell)' transaction only when the MACD line value exceeds (goes below) the 
Signal line value by more than 0.03 which corresponds to a 3 percent margin of safety. The third strategy is to execute a 'buy (sell)' transaction only when the minimum difference between the MACD line value and the Signal line value exceeds $0.5,1.1$ or 3.5 percent of the closing price after waiting for three consecutive similar signals. According to their logic, "the third strategy was proposed due to the fact that the application of the two aforementioned strategies did not contribute significantly to the reduction of false signals". Nevertheless, they found that all three non-conventional strategies did not outperform a "buy-and-hold" strategy which consisted of simply buying stocks at the beginning of the period then selling them at the end of the period. Hence, they concluded that, "In the long run, the MACD dynamic trades do not make sense since their potential profits are less than the static 'buy-and-hold' approach". Here again arises the question, "Why persist in using the traditional $(12,26,9)$ parameter settings?" If they had considered other values, they may have reached different conclusions.

In fact, prior to the above-mentioned studies, many researchers have already reported that the MACD does not produce good results by setting its parameters to the traditional values; they were not able to achieve good results by using the traditional MACD $(12,26,9)$ model.

Meissner et al. (2001) tested the effectiveness of the traditional MACD $(12,26,9)$ model and found that it results in a surprisingly poor success rate of 32.14 percent for the DOW 30 stocks and 32.73 percent for the individually tested NASDAQ-100 stocks over the 19891999 period. From these results, they concluded that the traditional MACD indicator can almost be regarded as a contra-indicator. Armour et al. (2010, cited by Anghel 2015) also tested the traditional MACD $(12,26,9)$ trading rule, including a simple moving average rule on 20 years of data for the Irish Stock Market Main Index and found that the MACD rule underperformed the buy-and-hold strategy. Chen and Metghalchi (2012) investigated the predictive power of 32 models of single, double or triple-indicator combinations based on the most popular six technical indicators for the Brazilian stock index (BOVESPA) over the period of 1996 to 2011 and found that none of the trading models, including the MACD $(12,26,9)$ model, can beat a buy-and-hold strategy. The results did not support the predictive power of technical analysis, thus they concluded that the Brazilian stock index was weak-form efficient. Abbey and Doukas (2012) tested whether the MACD $(12,24)$ model and three other well-known technical analysis indicators were profitable for five currencies for individual currency traders. Using a proprietary database of 428 individual currency traders over the period March 2004 to September 2009, they found that the four popular technical indicators had negative performance and concluded that this result arose because individual currency traders used well-known technical indicators to trade currencies, which implied that such currency traders suffer from reduced performance. Rosillo et al. (2013) examined which of four popular technical analysis tools, including the traditional MACD $(12,26,9)$ model achieved greater profitability for the companies of the Spanish Continuous Market from 1986 to 2009. Although they presented just one example of results for the Telefonica Company, the total net benefits generated by applying the MACD model were an unsatisfactory 2.48 percent. Du Plessis (2013) examined the MACD $(12,26,9)$ model and a buy-and-hold strategy to determine which was more effective for the South African stock market index (FTSE/JSE Top 40) over the period of 2001 to 2010. He found that the traditional MACD model was less effective than a buy-and-hold strategy. Based on this result, he stated that the MACD was not an effective investment strategy using the default settings in the market.

As can be seen from the above discussion, many researchers have failed to find satisfactory results for the MACD indicator by using its traditional parameter settings and have drawn negative conclusions for it. Yet, these researchers did not explore the optimality of the MACD's traditional parameters.

Based on the above-mentioned points, it is clear that: (1) there is no compelling need to stick to the traditional parameter value settings, since these parameter values are not a genuine standard, and further, that there could be more profitable value combinations; (2) 
the three parameter values should be selected in a more systematic way, and be specifically designed for each market, since the trading signals of the MACD model depend on the parameter values and their profitability is a consequence of these values; and, (3) optimizing the three parameter values should take precedence over searching for supplementary trading strategies to avoid false trade signals. Such an approach is both prudent and far more efficient than blindly searching for strategies at random without the benefit of parameter optimization.

\section{Preliminaries}

The formulas for the elements of the MACD indicator and brief remarks about the limitations of the indicator are presented in this section.

\subsection{The MACD Trading Indicator}

The MACD trading indicator consists of the following three elements:

- The MACD line: the difference between the short- and long-term exponential moving averages (EMA).

- The Signal line: an exponential moving average of the MACD line.

- Histogram: a graphical representation of the distance between the MACD line and the Signal line.

The EMA is defined as:

$$
E M A_{t}=\left[\frac{2}{n+1}\left(P_{t}-E M A_{t-1}\right)\right]+E M A_{t-1}
$$

where $n$ is the number of periods for the EMA and $P_{t}$ indicates the closing day price (index value) at time $t$. Let $n_{1}$ be the number of short-term and $n_{2}$ be the number of long-term periods. Then, EMAs of the two different periods can be presented as:

$$
\begin{aligned}
& E M A_{t}\left(n_{1}\right)=\left(2 /\left(n_{1}+1\right) \times\left(P_{t}-E M A_{t-1}\left(n_{1}\right)\right)+E M A_{t-1}\left(n_{1}\right)\right. \\
& E M A_{t}\left(n_{2}\right)=\left(2 /\left(n_{2}+1\right) \times\left(P_{t}-E M A_{t-1}\left(n_{2}\right)\right)+E M A_{t-1}\left(n_{2}\right)\right.
\end{aligned}
$$

Using the above equations, the three elements of the MACD indicator are formulated as follows:

$$
\begin{gathered}
\operatorname{MACD}_{t}\left(n_{1}, n_{2}\right)=E M A_{t}\left(n_{1}\right)-\operatorname{EMA}_{t}\left(n_{2}\right) \\
\text { Signal }_{t}\left(n_{3}\right)=\left(2 /\left(n_{3}+1\right) \times\left(M A C D_{t}\left(n_{1}, n_{2}\right)-\operatorname{Signal}_{t-1}\left(n_{3}\right)\right)+\operatorname{Signal}_{t-1}\left(n_{3}\right)\right. \\
\text { Histogram }_{t}=M A C D_{t}-\text { Signal }_{t}
\end{gathered}
$$

where $n_{3}$ denotes the period for the EMA calculation of the $M A C D_{t}$ series. The MACD line, the Signal line and the Histogram can be created from Equations (4)-(6), respectively. As can be seen from the equations, the three elements (the MACD line, the Signal line, and the Histogram) move above and below the zero line. Again, the MACD indicator depends on the time constants for the EMAs, which are usually represented in the form of "MACD $\left(n_{1}, n_{2}, n_{3}\right)^{\prime \prime}$, e.g., $\operatorname{MACD}(12,26,9)$.

\subsection{MACD Trading Rules}

The two trading rules mentioned in the first section, "zero crossover" and "signal line crossover" can be expressed as follows:

$$
\begin{aligned}
& \text { zero crossover }=\left\{\begin{array}{l}
\text { Buy, when } M A C D_{t}\left(t_{1}, t_{2}\right)=E M A_{t}\left(t_{1}\right)-E M A_{t}\left(t_{2}\right)>0 \\
\text { Sell, when } M A C D_{t}\left(t_{1}, t_{2}\right)=E M A_{t}\left(t_{1}\right)-E M A_{t}\left(t_{2}\right)<0
\end{array}\right. \\
& \text { signal line crossover }=\left\{\begin{array}{l}
\text { Buy, when Histogram } \\
\text { Sell, when Histogram } \\
\text { Sh }=M A C D_{t}-\text { Signal }_{t}>0 \\
\text { Signal }_{t}<0
\end{array}\right.
\end{aligned}
$$


Some researchers and practitioners use the former. However, the latter will be adopted in this study since it is more commonly used these days. We will refer to the latter as the basic MACD trading rule hereafter.

\subsection{Limitations of the MACD Model}

As is the case with other technical analysis tools, the MACD indicator can generate false signals. This is because the MACD model is based on moving averages of past prices that have already taken place. In other words, the MACD model lags the market price to a greater or lesser degree and thus trend reversals are detected only after they actually happen. Due to the inherit limitations of this approach to timing, executing a trade at the point of signal line crossover can turn out to be a false transaction signal. Such situations often occur when a signal line crossover indicates a potential buying point, but market conditions are still considered to be bearish. In contrast a false sell signal occurs when the crossover calls for a sell, but market conditions are still likely to be bullish.

Analysts therefore use a variety of approaches to filter out such false trade signals and verify valid trade signals. Three different trading strategies were described by Hejase et al. (2017). However, no matter which approach is taken, one thing is obvious: the more we try to reduce the frequency of false trade signals, the more likely we are to lose profitable opportunities-assuming that the MACD model is basically valid. This implies that we must accept a certain level of false signal generation; nevertheless, we have to improve the ability to validate transaction signals since there is no perfect way to predict and eliminate all false signals. One approach is to change the three parameter values of the MACD to control the frequency of signal generation (i.e., sensitivity). For example, when calibrating for greater sensitivity, we could use a smaller moving average. Conversely, when adjusting to have less sensitivity to reduce false trade signals, we might lengthen the moving average. We can see from this logic that it is important to adjust the three parameter values for each market.

\section{Research Methodology}

As described in the Section 1, three types of models are tested in this study: the model with the traditional parameter value settings, models with different parameter combinations, and models for which the trading rule is modified by applying a systematic approach to avoid false signals. The first-, the second- and the third-types of model will be referred to hereafter as the "traditional model", "comparative models", and "modified models", respectively. In addition, models with more-optimized, better-fitted parameter values for the Japanese market will be referred to as the "optimized model".

This study uses basic trading simulations to determine the profitability of the tested models. For the test of profitability of all models mentioned above, the daily closing index values of Nikkei 225 Futures contracts near maturity over the past nine years (4 January 2011 to 30 December 2019) were obtained from an official data provider, JPX Data Cloud (http:/ / db-ec.jpx.co.jp). The Nikkei 225 includes the top 225 blue-chip companies listed on the Osaka Exchange of the Japan Exchange Group (JPX); it is the primary yen-denominated stock index future.

\subsection{Common Matters for Trading Simulations}

This study adopts the "signal line crossover" trading rule described by Equation (8) for the test of profitability of all models. As for determining the buying and selling times in simulation, we execute as follows. When a 'buy (or sell)' signal is generated according to the signal line crossover, a buy (or sell) order for 'one trading unit' is executed at the closing price (index value) on the next day. After having opened a 'buy (or sell)' position, all subsequent identical buy (or sell) signals are ignored. However, when the first opposite trading signal from the opening position, i.e., 'sell (or buy)' signal is generated, the buy (or sell) position is assumed to be closed out at the closing price reported on the next day. At the same time, in order to implement the newly generated signal, a new 'sell (or buy)' 
order for one trading unit is assumed to be executed at the same closing price of the same day. That is, when a position is closed, a reverse trade is automatically executed. Another assumption made with regard to the calculation of profitability is that all trades must be settled by the last trading day of the contract.

As previously stated, only one position for 'one unit' can be open at a time and all transactions have to be executed one-by-one sequentially. This means that holding multiple positions is not permitted after a position is taken. This assumption is for convenience in calculating trading returns and to facilitate comparisons with the returns of various models which have different parameter values.

One contract unit on the Nikkei 225 Futures for a large contract is 1000 times the value of the Nikkei 225 index value and its tick size is 10 Japanese yen (JPY). Therefore, one tick up for a one-unit contract leads to a positive return of JPY 10,000 $(=10 \times 1000)$. On the other hand, the current round-trip commission for one large contract unit is approximately JPY 330 in the case of an over-the-counter transaction on almost all Japanese trading websites. Thus, if the index moves 10 ticks (100), the commission of JPY 330 corresponds to, at best 0.33 percent of the positive or negative return of JPY 100,000; in the case of a 100 tick move, 0.033 percent and so on. That is, the round-trip commission of JPY 330 is so small that it can be ignored, compared to the high leverage at 1000 times the index value. Thus, this tiny commission will not be taken into consideration in this study. Accordingly, the return of each transaction is calculated as:

$$
r_{\text {sell-buy }}=P_{\text {sell }}-P_{b u y}
$$

where $P_{b u y}$ and $P_{\text {sell }}$ are the closing index values on the days to execute buying and selling transactions. A positive (negative) value of Equation (9) indicates a profit (loss), which is applicable in both the case of a long and a short trade. In the following Section 5.6, $\log$ returns are calculated for every transaction to report test results of whether the difference in the returns between a modified model and the traditional model is statistically significant.

\subsection{Tests of the Performance of the Traditional Model}

In order to explore the first check point mentioned at the end of Section 1, we divide the whole sample into three fairly long sub-periods: 2011-2013, 2014-2016 and 20172019 following the approach of Chong and $\mathrm{Ng}$ (2008). This means that the calculation of profitability for every model is carried out in each sub-period separately for robustness in choice of sample period. That is, we fit the model to a prior set of data and then tested it on a later out-of-sample set of data.

\subsection{Tests of the Performance of the Comparative Models}

In order to explore the second check point mentioned at the end of Section 1 and verify the validity of the first two assumptions stated at the end of Section 2, we search for new parameter combinations that outperform the traditional MACD $(12,26,9)$ model. For the purpose, the three parameters of the $\operatorname{MACD}\left(n_{1}, n_{2}, n_{3}\right)$ are taken into consideration over a given range as follows: $n_{1}=\{3,4, \cdots, 20\}, n_{2}=\{5,6, \cdots, 40\}, n_{3}=\{3,4, \cdots, 40\}$, where each is at an interval of one day. This approach produces $24,624(=18 \times 36 \times 38)$ unique sample models in total, starting from the MACD $(3,5,3)$ model and ending with the MACD $(20,40,40)$ model. However, this approach produces $5168(=(16+15+\cdots+1) \times 38)$ irrational models where the value of the short-term parameter is greater than or equal to the value of long-term parameter. Accordingly, 19,456 (=24,624 - 5168) models are examined in this study.

Among the models examined in this study, there were many for which the return in the first subperiod was higher than that of the traditional MACD $(12,26,9)$ model. However, we evaluated their performance not only on their return but also in terms of the rate of profitable trades, the rate of unprofitable trades and the number of total trades from the perspectives of actual traders. By filtering the results of each model, we excluded models for which returns were high but that had a high ratio of unprofitable trades and/or the 
actual number of total trades was low from the pool of good performance models. ${ }^{1}$ As a result, we chose the MACD $(4,22,3)$ model as a good model. It is balanced in terms of profit acquisition and loss avoidance, and has enough transactions to satisfy traders who trade on a short-term basis. This is why we chose the MACD $(4,22,3)$ model as an example model to be compared with the traditional MACD $(12,26,9)$ model.

\subsection{Tests of the Performance of the Modified Models}

In order to explore the third check point mentioned at the end of Section 1 and verify the validity of the third assumption stated at the end of Section 2, we prepared the following three systematic strategies to avoid false signals and compared the effect of applying the additional trading strategies to the aforementioned MACD $(4,22,3)$ model and the traditional MACD $(12,26,9)$ model. We will also extend our analysis to other models with better-optimized parameter values to check the general result. This includes models with non-optimized parameter values for robustness.

In evaluating the effectiveness of the three modified strategies, a standard $t$-test is utilized in this study in line with the existing literature. The null hypothesis of equality between the mean return of the model with any of the three modified strategies $\left(\mu_{1}\right)$ and that of the traditional model $\left(\mu_{2}\right)$, i.e., $\mathrm{H}_{0}: \mu_{1}=\mu_{2}$ is tested against the alternative hypothesis $\mathrm{H}_{1}: \mu_{1}>\mu_{2}$. The same approach is used for tests of the difference in mean returns for long (buy signals) and short trades (sell signals) of the two models to be compared.

\subsubsection{A: The $n$-Day Holding Strategy}

For the reason stated above, this strategy considers any closing signal(s) generated according to a signal line crossover within the first few days after opening a position to be false trade signal(s) and holds the current position for a minimum number of day(s). Accordingly, the trading rule adopted by this strategy is stated as: to open a position by following a signal generated by the trading rule of a signal line crossover and to ignore closing signals generated 'within a given few days' and finally then close the position when the next new closing signal is generated. More formally,

$$
\text { opening signal }=\left\{\begin{array}{l}
\text { Buy }: H_{t_{i}}>0 \\
\text { Sell }: H_{t_{i}}<0
\end{array}, \text { closing signal }=\left\{\begin{array}{l}
\text { Sell }: H_{t_{j}}<0, j>i+n \\
\text { Buy }: H_{t_{j}}>0, j>i+n
\end{array}\right.\right.
$$

where $H_{t}$ indicates the histogram at day $t ; t_{i}$ is the day that an opening signal is generated; $n$ is the minimum number of day(s) that the position should be held; and, $t_{j}$ is the day that a closing signal is generated after the minimum holding period. For parameter setting, we let $n=\{1,2, \cdots, 5\}$ in this study. But we will discuss the case of ' $n=1^{\prime}$ ' as an example of the most profitable strategy and we will refer to this strategy as the '1-day' holding strategy in the following sections.

\subsubsection{B: The $x \%$-Line Crossover of $y$-Day-Histogram Strategy}

As another way to avoid the false signals of the MACD, this strategy focuses on confirming whether the value of the current histogram reaches a certain size relative to the zero line-not just crossing over the zero line. More specifically, it is stated as: only if the current histogram crosses up (down) through a $x \%$ line extending below (above) the zero line to the highest (lowest) histogram over the previous y days, go long (short). This strategy can be expressed as follows, to open a position by following the buy or sell signal stated below and close the position by following its opposite trading signal:

$$
\begin{aligned}
& \text { Buy : } H_{t}>x * \min \left\{H_{t-y}, \cdots, H_{t-1}, H_{t}\right\},\left\{H_{t-y}, \cdots, H_{t-1}, H_{t}\right\}<0 \\
& \text { Sell : } H_{t}<x * \max \left\{H_{t-y}, \cdots, H_{t-1}, H_{t}\right\},\left\{H_{t-y}, \cdots, H_{t-1}, H_{t}\right\}>0
\end{aligned}
$$

1 For example, MACD $(5,17,14)$ produced a higher return than the MACD $(4,22,3)$ model, but its rate of unprofitable trades was higher and the number of total trades was also lower. 
We parameterize $x=\{0.5,0.1, \cdots, 0.95,1.00\}$ and $y=\{5,6, \cdots, 120\}$ to get a total of 2280 strategies. However, we will only discuss the case of $x=0.3(30 \%$ ) and $y=10$ (days), which is as an example of the most profitable strategy. We will refer to this strategy as either the ' $30 \%$-line of 10 -day' or the "30\%10d" strategy hereafter.

\subsubsection{C: The First Peak/Bottom Point of the Histogram Search Strategy}

A trader can consider a peak (bottom) point of the histogram as a turning point in the market trend (trend reversal) - instead of waiting for the histogram to reach a certain size as a second strategy. When such a situation is considered, this strategy directs the trader to wait until he/she finds the first apparent peak (bottom) point of the histogram. To be more specific, it states: only if histogram values over the most recent three consecutive days are all below (above) the zero line and the histogram of the middle day is the lowest (highest) among the three days' histograms, go long (short). This strategy can be formally expressed:

$$
\begin{aligned}
& \text { Buy : } H_{t-1}=\min \left\{H_{t-2}, H_{t-1}, H_{t}\right\},\left\{H_{t-2}, H_{t-1}, H_{t}\right\}<0 \\
& \text { Sell : } H_{t-1}=\max \left\{H_{t-2}, H_{t-1}, H_{t}\right\},\left\{H_{t-2}, H_{t-1}, H_{t}\right\}>0
\end{aligned}
$$

We examine other ways to find the first apparent peak (bottom) point over the most recent five or seven consecutive days' histograms and furthermore what happens if we define the turning point of the market as not the first but rather as the second or third peak (bottom) point. However, as an example of the most profitable strategy, we will discuss only the case stated above. This strategy is referred to as the search for 'the first-peak/bottom-point' or the '1st-pkbm' strategy hereafter.

\section{Empirical Results}

In the 19,456 models examined in this study, there were many for which the profitability over the full 9 years was higher than that of the traditional MACD $(12,26,9)$ model. Yet, to enumerate all the better performing models is not the main point and would divert us from the purpose of this study. Furthermore, there is space here for only one or two examples. Therefore, as an example of these superior models, returns from the MACD $(4,22,3)$ model are presented below. From these, we can see that there are more profitable parameter value settings than the traditional settings. Having made this point, we turn to see the effect of using the three additional trading strategies (1-day, 30\%10d and 1st-pkbm) to all models examined in this study.

\subsection{An Overview of the Nikkei 225 Futures over the Past Nine Years}

Before examining the empirical results, let us begin with a simple observation on the changes in the trends in the Nikkei 225 Futures values. This will help interpret the results presented below. The thick line at the top of Figure 1 shows how the index changes from 4 January 2011 to 30 December 2019 (which covers 2204 trading days). The bottom three lines show an MACD line (red), a signal line (blue) and a histogram chart (green) for the traditional MACD $(12,26,9)$ model.

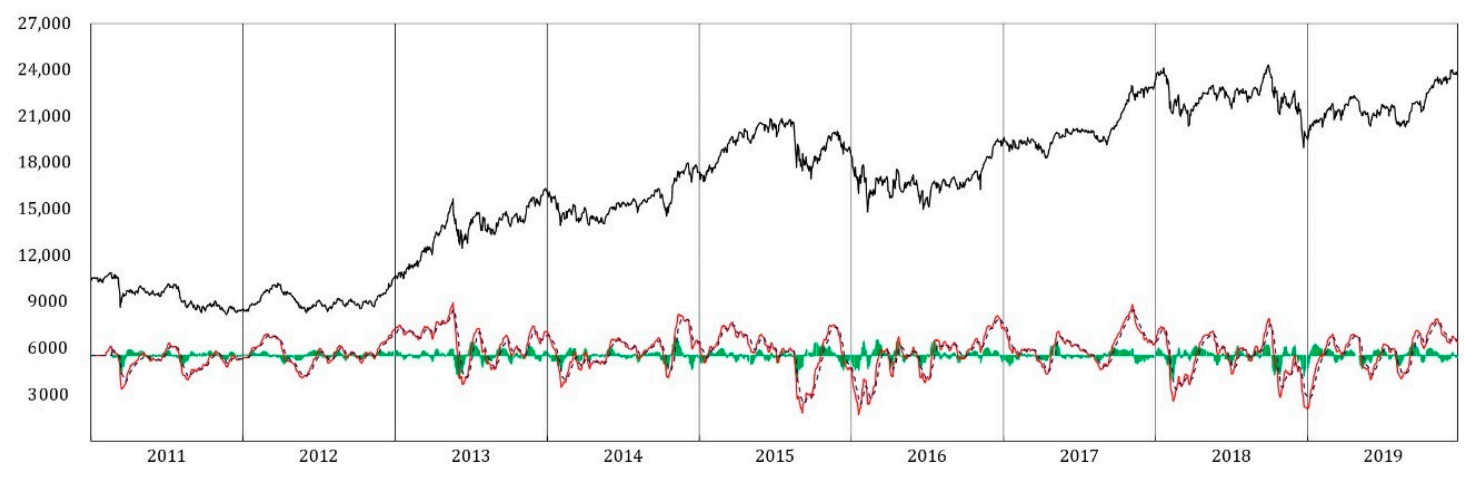

Figure 1. Index Value of Nikkei 225 Futures and MACD $(12,26,9)$ over the past 9 years. 
As we can see from the figure, the index value goes up suddenly from the beginning of 2013 and then manifests a long-term increasing trend to the end of 2019. The latter period is quite different from the relatively stable levels of the period before 2013 (in fact, the stable flat trend to the end of 2012 goes back to 2009). This suggests that we should take the difference in periods into consideration in analyzing and interpreting the trading results. We therefore divide the whole period, as was stated in Section 4.2, into three sub-periods: 2011-2013, 2014-2016 and 2017-2019.

As for the increasing trend from the beginning of 2013, the following two expansionary monetary policies seem to have played a role: the first is the third round of quantitative easing (QE3: September 2012-October 2014) implemented by the Federal Reserve Board of the United States, and the other is the large-scale asset purchase program started in April 2013 (at a higher level than in previous years) by the Bank of Japan. As for the increasing trend from the middle of 2016, it seems to be related to the Bank of Japan's monetary easing in September 2016, in addition to its negative interest rate policy from January 2016.

\subsection{The Performance of the Traditional MACD $(12,26,9)$ Model}

Note that the profitability of this model is shown here by its raw returns to facilitate comparison with the returns of other models to be discussed later.

The first two columns ' $\mathrm{N}(\mathrm{Buy})$ ' and ' $\mathrm{N}($ Sell)' in Table 1 indicate the number of long and short trades; these are the buy and sell signals generated by the trading rule. The next two columns ' $\mathrm{N}($ Buy $>0)$ ' and ' $\mathrm{N}($ Sell $>0)$ ' show the number of profitable long and short trades, where the numbers inside the parentheses show the proportions of the trades that are profitable. 'Buy' and 'Sell' show returns from long and short trades, while 'Buy + Sell' indicates the total return of those trades. ' $\mathrm{N}($ Buy $)+\mathrm{N}($ Sell)' shows the total number of long and short trades. The last column ' $\mathrm{N}($ Buy $<0)+\mathrm{N}($ Sell $<0)$ ' is the total number of unprofitable long and short trades, where the numbers inside the parentheses indicate the proportions of trades that are losses.

Table 1. The Performance of the Traditional MACD $(12,26,9)$ Model.

\begin{tabular}{|c|c|c|c|c|c|c|c|c|c|}
\hline & N(Buy) & N(Sell) & $\mathrm{N}($ Buy $>0)$ & $\mathrm{N}($ Sell >0) & Buy & Sell & Buy + Sell & N(Buy) + N(Sell) & $\mathrm{N}($ Buy $<0)+\mathrm{N}($ Sell $<0)$ \\
\hline Whole period & 84 & 85 & $33(0.393)$ & $20(0.235)$ & 5430 & -9610 & -4180 & 169 & $116(0.686)$ \\
\hline 2011-2013 & 28 & 29 & $13(0.464)$ & $8(0.276)$ & 3230 & -2370 & 860 & 57 & $36(0.632)$ \\
\hline 2014-2016 & 31 & 31 & $11(0.355)$ & $8(0.276)$ & 780 & -4290 & -3510 & 62 & $47(0.758)$ \\
\hline 2017-2019 & 25 & 25 & $9(0.360)$ & $8(0.320)$ & 1420 & -2950 & -1530 & 50 & $33(0.660)$ \\
\hline
\end{tabular}

The first point to observe is that the MACD $(12,26,9)$ model earns a surprisingly large 'minus 4180 ' for the whole period, which means a capital loss of JPY 4,180,000 $(=4180 \times 1000$, approximately 40,200 US dollars based on the current exchange rate of $¥ / \$=104)$. The second point is that the proportion of unprofitable trades is 0.686 . These results are far from satisfactory. In fact, the total return for this model, 'minus 4180', is ranked at 10,636th among the 19,456 models examined in this study. Another noteworthy point is that the returns in the second and third sub-periods are at 'minus 3510' and 'minus 1530'. This suggests that in an overall up-trend market environment as illustrated in Figure 1, we cannot expect good performance from the traditional MACD $(12,26,9)$ model. Moreover, it is reasonable to expect that the investment model should beat or at least match a simple buy-and-hold investment strategy.

\subsection{The Performance of the Example MACD $(4,22,3)$ Model}

As can be seen from Table 2, using the MACD $(4,22,3)$ model has produced positive returns of 9420 over the whole period, which is higher than the negative return $(-4180)$ of the traditional MACD $(12,26,9)$ model. This outstanding performance over the whole period can be understood to be a result of the higher proportion of 'profitable' trades than the traditional MACD $(12,26,9)$ model. Over the whole period, the proportions of $\mathrm{N}($ Buy $>0)$ and $\mathrm{N}($ Sell $>0)$ of the MACD $(4,22,3)$ model exceed those of the MACD $(12,26,9)$ model. Especially, this model yielded positive returns in the second and in the third sub- 
periods, while the MACD $(12,26,9)$ model experienced negative returns. Note that these improvements are achieved by changing only the three parameter values from $(12,26,9)$ to $(4,22,3)$. This point should be given added emphasis-it is a main result of this research.

Table 2. The Performance of the Example MACD $(4,22,3)$ Model.

\begin{tabular}{cccccccccc}
\hline & N(Buy) & N(Sell) & N(Buy > 0) & N(Sell > 0) & Buy & Sell & Buy + Sell & N(Buy) + N(Sell) & N(Buy < 0) + N(Sell < 0) \\
\hline Whole period & 217 & 217 & $107(0.493)$ & $79(0.364)$ & 12,040 & -2620 & 9420 & 434 \\
$2011-2013$ & 74 & 75 & $37(0.500)$ & $29(0.387)$ & 3030 & -2160 & 870 & $248(0.571)$ \\
$2014-2016$ & 62 & 62 & $31(0.500)$ & $20(0.323)$ & 3700 & -960 & 2740 & $83(0.557)$ & 149 \\
$2017-2019$ & 81 & 80 & $39(0.481)$ & $30(0.375)$ & 5310 & -500 & 5810 & 124 & 161 \\
\hline
\end{tabular}

\subsection{The Effects of Applying the Three Trading Strategies to the MACD $(4,22,3)$ Model}

Although the aforementioned MACD $(4,22,3)$ model achieved high profitability, its proportion of unprofitable trades was still high. Consider again the column labeled ${ }^{\prime} \mathrm{N}($ Buy $<0)+\mathrm{N}($ Sell $<0)$ ' in Table 2. The proportion of unprofitable trades can be interpreted as a ratio that results from following false signals, thus we will define it as the 'ratio (or numbers) of false signals' hereafter. Then, the next item to be discussed is how we can avoid false trade signals and reduce this ratio. For this purpose, we considered in Section 4.4 three modified trading strategies by adjusting the trading rule for the MACD $(4,22,3)$ model. Below are the results.

\subsubsection{The One-Day Holding Strategy}

We can see from Table 3 that the MACD $(4,22,3)$ model with the 1-day holding strategy did do better in avoiding false trade signals and enhanced profitability.

Table 3. The Performance of the $\operatorname{MACD}(4,22,3)$ Model with the 1-day Minimum Holding Strategy.

\begin{tabular}{|c|c|c|c|c|c|c|c|c|c|}
\hline & N(Buy) & $\mathrm{N}($ Sell) & $\mathrm{N}($ Buy $>0)$ & $\mathrm{N}($ Sell $>0)$ & Buy & Sell & Buy + Sell & $\mathrm{N}($ Buy) + N(Sell) & $\mathrm{N}($ Buy $<0)+\mathrm{N}($ Sell $<0)$ \\
\hline Whole period & 155 & 155 & $81(0.523)$ & $59(0.381)$ & 17,070 & 2900 & 19,970 & 310 & $170(0.548)$ \\
\hline 2011-2013 & 48 & 49 & $28(0.583)$ & $19(0.388)$ & 4340 & -610 & 3730 & 97 & $50(0.515)$ \\
\hline 2014-2016 & 51 & 51 & $25(0.490)$ & $17(0.333)$ & 4710 & 50 & 4760 & 102 & $60(0.588)$ \\
\hline 2017-2019 & 56 & 55 & $28(0.500)$ & $23(0418)$ & 8020 & 3460 & 11,480 & 111 & $60(0.541)$ \\
\hline
\end{tabular}

In comparison with the original MACD $(4,22,3)$ model, 'the number of false signals' over the whole period was reduced from 248 to 170 (down almost 31.5\%) by applying the minimum 1-day holding strategy, while 'the number of trades' was reduced from 434 to 310 (down almost $28.6 \%$ ). Hence, the proportional decline in 'the number of false signals' is higher than the decline in 'the number of trades'. This raises the return over the whole period from 9420 to 19,970 (almost 2.1 times larger). Specifically, the returns in every sub-period increased from 870 to 3730 (up almost 4.3 times), from 2740 to 4760 (up almost 1.7 times) and from 5810 to 11,480 (up almost 2.0 times).

It is interesting to note that all of the aforementioned results were obtained just by imposing a rule to hold the current position for at least one day to the original MACD $(4,22,3)$ model. In comparison with the traditional MACD $(12,26,9)$ model, the return over the whole period had increased from ' -4180 ' to 19,970 .

\subsubsection{The 30\%-Line of the 10-Day-Histogram Crossover Strategy}

This strategy also did better in avoiding false signals and enhancing profitability. Consider the results shown in Table 4 . By adopting this strategy to the original MACD $(4,22,3)$ model, 'the number of false signals' over the whole period was reduced from 248 to 159 (down almost 35.9\%), while 'the number of trades' was reduced from 434 to 312 (down almost $28.1 \%$ ). This greatly improves the returns over the whole period from 9420 to 22,690 (almost 2.4 times larger). As was the case for the minimum 1-day holding strategy, the returns in every sub-period also increased compared to the original model. 
Table 4. The Performance of the MACD $(4,22,3)$ Model with the 30\%-Line of the 10-Day Crossover Strategy.

\begin{tabular}{|c|c|c|c|c|c|c|c|c|c|}
\hline & N(Buy) & N(Sell) & $\mathrm{N}(\mathrm{Buy}>0)$ & $\mathbf{N}($ Sell >0) & Buy & Sell & Buy + Sell & $\mathrm{N}($ Buy $)+\mathrm{N}($ Sell) & $\mathrm{N}($ Buy $<0)+\mathrm{N}($ Sell $<0)$ \\
\hline $\begin{array}{l}\text { Whole } \\
\text { period }\end{array}$ & 155 & 157 & $85(0.548)$ & $68(0.433)$ & 18,510 & 4180 & 22,690 & 312 & $159(0.510)$ \\
\hline $2011-2013$ & 54 & 55 & $27(0.500)$ & $20(0.364)$ & 4300 & -780 & 3520 & 109 & $62(0.569)$ \\
\hline 2014-2016 & 47 & 48 & $27(0.574)$ & $22(0.458)$ & 6470 & 1670 & 8140 & 95 & $46(0.484)$ \\
\hline 2017-2019 & 54 & 54 & $31(0.574)$ & $26(0481)$ & 7740 & 3290 & 11,030 & 108 & $51(0.472)$ \\
\hline
\end{tabular}

\subsubsection{The Search for the First Peak/Bottom Point of the Histogram Strategy}

Almost the same result as was found above can be seen for this strategy. Consider Table 5. Introducing this strategy to the original $\operatorname{MACD}(4,22,3)$ model reduced 'the number of false signals' over the whole period from 248 to 207 (down almost 16.5\%), while 'the number of trades' changed little-from 434 to 437 . As a result, the return over the whole period increased from 9420 to 20,950 (almost 2.2 times larger). Of special note is the ' 15,750 ' return in the second sub-period, which is the highest among all returns in sub-periods produced by adopting all three strategies.

Table 5. The Performance of the MACD $(4,22,3)$ Model with the Search for First Peak/Bottom-Point Strategy.

\begin{tabular}{cccccccccc}
\hline & N(Buy) & N(Sell) & N(Buy > 0) & N(Sell > 0) & Buy & Sell & Buy + Sell & N(Buy) + N(Sell) & N(Buy < 0) + N(Sell < 0) \\
\hline Whole & 218 & 219 & $122(0.560)$ & $108(0.493)$ & 18,020 & 2930 & 20,950 & $207(0.474)$ \\
period & 75 & 75 & $37(0.493)$ & $34(0.453)$ & 750 & -4560 & -3810 & 437 \\
$2011-2013$ & 62 & 63 & $40(0.645)$ & $37(0.587)$ & 10,340 & 5410 & 15,750 & 150 \\
$2014-2016$ & 81 & 81 & $45(0.556)$ & $37(0.457)$ & 6930 & 2080 & 9010 & 125 & 162 \\
$2017-2019$ & $810.527)$ & $80(0.494)$ & $164)$ \\
\hline
\end{tabular}

\subsection{The Effects of Applying the Three Trading Strategies to the Traditional MACD $(12,26,9)$ Model}

Table 6 shows the results for the three strategies applied to the traditional model. It presents trading results for only the whole period to make comparisons simple. As can be seen from the table, the returns ('Buy + Sell') are all negative. Clearly, these three strategies did not improve the performance of the traditional model. This means that strategies intended to avoid false trade signals do not in themselves earn profits.

Table 6. The Performance of the Traditional MACD $(12,26,9)$ Model with the Three Strategies.

\begin{tabular}{|c|c|c|c|c|c|c|c|c|c|}
\hline & N(Buy) & N(Sell) & $\mathrm{N}($ Buy $>0)$ & N(Sell > 0) & Buy & Sell & Buy + Sell & $\mathrm{N}($ Buy) + N(Sell) & $\mathrm{N}($ Buy $<0)+\mathrm{N}($ Sell $<0)$ \\
\hline \multicolumn{10}{|c|}{ A: Performance of MACD $(12,26,9)$ with the 1-day holding strategy } \\
\hline Whole Period & 72 & 73 & $32(0.444)$ & $17(0.233)$ & 7120 & -7920 & -800 & 145 & $96(0.662)$ \\
\hline \multicolumn{10}{|c|}{ B: Performance of MACD $(12,26,9)$ with the $30 \%$-line crossover of 10 -days strategy } \\
\hline Whole Period & 72 & 72 & $34(0.472)$ & $22(0.306)$ & 3430 & $-11,630$ & -8200 & 144 & $88(0.611)$ \\
\hline \multicolumn{10}{|c|}{ C: Performance of MACD $(12,26,9)$ with the pick finding strategy } \\
\hline Whole Period & 84 & 84 & $52(0.619)$ & 37 (0440) & 4400 & -8130 & -3730 & 168 & $79(0.470)$ \\
\hline
\end{tabular}

\subsection{Tests of Statistical Significance}

The following are tests of whether the difference in the returns between the sample $\operatorname{MACD}(4,22,3)$ model with each of the three strategies and the traditional MACD $(12,26,9)$ model are statistically significant. For the test, $\log$ returns are calculated (for every transaction) to construct a return series of the difference in the monthly returns of the two models. Monthly returns are used because they are less noisy than the weekly and daily returns. Figure 2 shows the daily/monthly log return of the series for reference. 


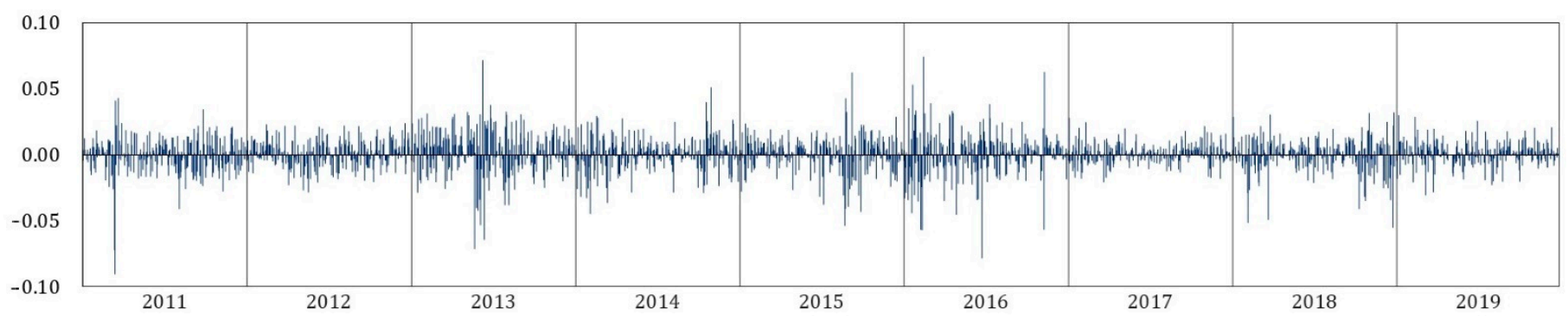

(a)

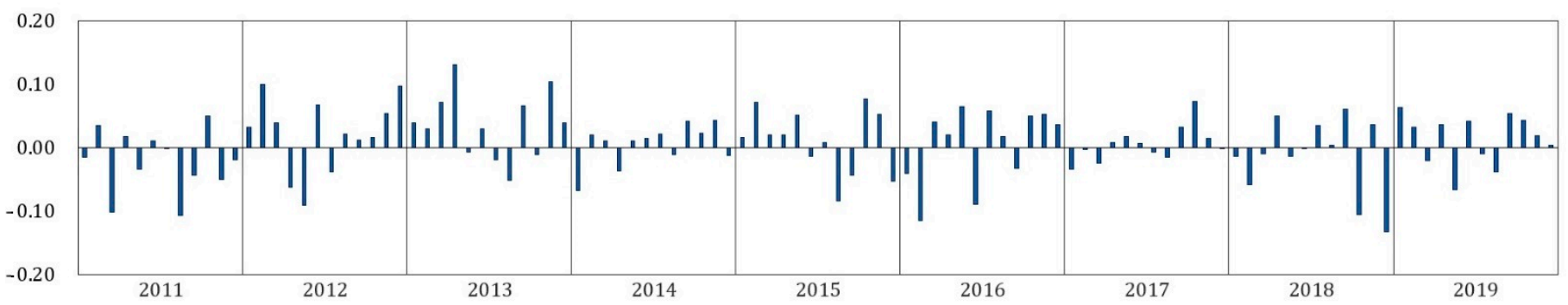

(b)

Figure 2. (a). Time Plot of the Daily Log Returns of Nikkei 225 Futures. (b). Time Plot of the Monthly Log Returns of Nikkei 225 Futures.

Table 7 summarizes the descriptive characteristics for the daily log returns of the Nikkei 225 index values for reference. It shows that the returns in all periods are moderately skewed; the index is leptokurtic for the whole period as well as in all subperiods. In the second subsample, a reduction in skewness and kurtosis can be observed.

Table 7. Summary Statistics.

\begin{tabular}{ccccccc}
\hline & Min & Max & Mean & S.D & Skewness & Kurtosis \\
\hline Whole period & -0.0907 & 0.0742 & 0.0004 & 0.0134 & -0.5161 & 4.6747 \\
2011-2013 & -0.0907 & 0.0715 & 0.0006 & 0.0143 & -0.7136 & 4.9096 \\
$2014-2016$ & -0.0784 & 0.0742 & 0.0002 & 0.0151 & -0.2516 & 3.5101 \\
$2017-2019$ & -0.0554 & 0.0320 & 0.0003 & 0.0102 & -0.7154 & 3.5679 \\
\hline
\end{tabular}

5.6.1. The MACD $(4,22,3)$ Model with the '1-Day' Holding Strategy vs. the MACD $(12,26,9)$ Model

Table 8 presents the $t$-test output generated after comparing the returns of the MACD $(4,22,3)$ model with the minimum '1-day' holding strategy to the traditional 'MACD $(12,26,9)$ model. Note that the values in the columns labeled 'Buy', 'Sell' and 'Buy + Sell' show the mean returns of the trades; the figures inside the parentheses are the t-statistics; and, the values marked with ** and * show statistical significance at the 5 and 10 percent levels of confidence for one-tailed tests.

Table 8. $t$-test Output for the MACD $(4,22,3)$ Model with the minimum '1-day' Holding Strategy. vs. the MACD $(12,26,9)$ Model.

\begin{tabular}{|c|c|c|c|c|c|c|c|}
\hline & N(Buy) & N(Sell) & $\mathrm{N}($ Buy $>0)$ & $\mathbf{N}($ Sell > 0) & Buy & Sell & Buy + Sell \\
\hline Whole period & 108 & 108 & 0.523 & 0.381 & $\begin{array}{l}0.00924 \\
(1.1605)\end{array}$ & $\begin{array}{l}0.00115 \\
(1.2442)\end{array}$ & $\begin{array}{c}0.01039 \\
(1.7076) * * a\end{array}$ \\
\hline 2011-2013 & 75 & 75 & 0.583 & 0.388 & $\begin{array}{l}0.00995 \\
(0.2639)\end{array}$ & $\begin{array}{c}-0.00072 \\
(0.3523)\end{array}$ & $\begin{array}{l}0.00923 \\
(0.4458)\end{array}$ \\
\hline 2014-2016 & 62 & 63 & 0.490 & 0.333 & $\begin{array}{l}0.00730 \\
(0.6877)\end{array}$ & $\begin{array}{c}-0.00029 \\
(0.7902)\end{array}$ & $\begin{array}{l}0.00701 \\
(1.0505)\end{array}$ \\
\hline 2017-2019 & 81 & 81 & 0.500 & 0.418 & $\begin{array}{l}0.01046 \\
(1.1847)\end{array}$ & $\begin{array}{l}0.00446 \\
(1.2092)\end{array}$ & $\begin{array}{c}0.01492 \\
(1.6549) * b\end{array}$ \\
\hline
\end{tabular}


First of all, consider the $t$-statistics in the column labeled 'Buy + Sell' for the whole period. The null hypothesis (stated in Section 4.4) of the equality between the mean return of the MACD $(4,22,3)$ model with the minimum 1-day holding strategy and that of the traditional model is rejected at a significance level of 5 percent. The $p$-value $(0.0446)$ under the table also confirms that there is a significant difference between the returns of the two models. This result reveals that the mean return of the MACD $(4,22,3)$ model with the 1-day holding strategy is significantly greater than that of the traditional MACD $(12,26,9)$ model. To put it briefly, the former outperforms the latter. A significant difference is also found for the 'Buy + Sell' returns in the third sub-period.

\subsubsection{The MACD $(4,22,3)$ Model with the '30\%-Line of 10-Day' Strategy vs. the MACD} $(12,26,9)$ Model

Table 9 confirms that there is a significant difference between the returns of the two models stated in the title. The null hypothesis for the returns of 'Buy + Sell' for the whole period is rejected at a significance level of 5 percent, in the second sub-period at 10 percent, and in the third sub-period at 10 percent. Besides this, the null hypothesis for the returns of 'Sell' for the whole period is rejected at the 10 percent significance level.

Table 9. $t$-test Output for the MACD (4,22,3) Model with the '30\%10d' Strategy vs. the MACD $(12,26,9)$ Model.

\begin{tabular}{|c|c|c|c|c|c|c|c|}
\hline & N(Buy) & N(Sell) & $\mathrm{N}(\mathrm{Buy}>0)$ & $\mathrm{N}($ Sell $>0)$ & Buy & Sell & Buy + Sell \\
\hline Whole period & 108 & 108 & 0.548 & 0.433 & $\begin{array}{c}0.01002 \\
(1.2173)\end{array}$ & $\begin{array}{c}0.00187 \\
(1.4195) * \mathrm{~d}\end{array}$ & $\begin{array}{c}0.01190 \\
(1.8686) * a\end{array}$ \\
\hline 2011-2013 & 36 & 36 & 0.500 & 0.364 & $\begin{array}{l}0.00895 \\
(0.1576)\end{array}$ & $\begin{array}{c}-0.00187 \\
(0.2577)\end{array}$ & $\begin{array}{l}0.00708 \\
(0.3216)\end{array}$ \\
\hline 2014-2016 & 36 & 36 & 0.574 & 0.458 & $\begin{array}{l}0.01102 \\
(0.9156)\end{array}$ & $\begin{array}{l}0.00314 \\
(1.1866)\end{array}$ & $\begin{array}{c}0.01416 \\
(1.3661) * b\end{array}$ \\
\hline 2017-2019 & 36 & 36 & 0.574 & 0.481 & $\begin{array}{l}0.01009 \\
(1.0970)\end{array}$ & $\begin{array}{l}0.00436 \\
(1.1282)\end{array}$ & $\begin{array}{c}0.01445 \\
(1.6251) * \mathrm{c}\end{array}$ \\
\hline
\end{tabular}

$p$-value: ${ }^{\mathrm{a}}=0.0315,{ }^{\mathrm{b}}=0.0881,{ }^{\mathrm{c}}=0.0543,{ }^{\mathrm{d}}=0.0786 .{ }^{* *}$ and ${ }^{*}$ show statistical significance at the 5 and 10 percent levels of confidence for one-tailed tests.

5.6.3. The MACD $(4,22,3)$ Model with the Peak/Bottom Search Strategy vs. the MACD $(12,26,9)$ Model

Table 10 shows that there is a significant difference between the returns of the two models stated in the title. The null hypotheses for the returns of 'Buy + Sell' for the whole period and for the second sub-period are rejected at significance levels of 10 percent and 5 percent. Especially in the second sub-period, the null hypotheses for the returns of both 'Buy' and 'Sell' are rejected at significance levels of 5 percent and 10 percent, respectively.

Table 10. $t$-test Output for the MACD $(4,22,3)$ Model with the '1st-pkbm' Search Strategy vs. the MACD $(12,26,9)$ Model.

\begin{tabular}{|c|c|c|c|c|c|c|c|}
\hline & N(Buy) & N(Sell) & $\mathrm{N}($ Buy $>0)$ & $\mathrm{N}($ Sell > 0) & Buy & Sell & Buy + Sell \\
\hline Whole period & 218 & 219 & 0.560 & 0.493 & $\begin{array}{l}0.00858 \\
(0.9871)\end{array}$ & $\begin{array}{l}0.00006 \\
(0.9698)\end{array}$ & $\begin{array}{c}0.00864 \\
(1.3353) * a\end{array}$ \\
\hline 2011-2013 & 75 & 75 & 0.493 & 0.453 & $\begin{array}{l}-0.00031 \\
(-0.7158)\end{array}$ & $\begin{array}{l}-0.01142 \\
(-0.7120)\end{array}$ & $\begin{array}{l}-0.01172 \\
(-1.0113)\end{array}$ \\
\hline 2014-2016 & 62 & 63 & 0.645 & 0.587 & $\begin{array}{c}0.01704 \\
(1.7850)^{* * \mathrm{c}}\end{array}$ & $\begin{array}{c}0.00891 \\
(1.5735) * \mathrm{~d}\end{array}$ & $\begin{array}{c}0.02594 \\
(2.2475) * * b\end{array}$ \\
\hline 2017-2019 & 81 & 81 & 0.556 & 0.457 & $\begin{array}{l}0.00902 \\
(0.9798)\end{array}$ & $\begin{array}{l}0.00268 \\
(0.7950)\end{array}$ & $\begin{array}{l}0.01170 \\
(1.2000)\end{array}$ \\
\hline
\end{tabular}

$p$-value: ${ }^{\mathrm{a}}=0.0916,{ }^{\mathrm{b}}=0.0139,{ }^{\mathrm{c}}=0.0393,{ }^{\mathrm{d}}=0.0601 .{ }^{* *}$ and ${ }^{*}$ show statistical significance at the 5 and 10 percent levels of confidence for one-tailed tests. 


\subsection{A Reconsideration of the Evidence of Superior Performance of the Three Strategies}

From the results in the previous sections, we can assess whether the three additional strategies make it possible to improve MACD models by avoiding false signals. However, the effect was only observed in the example MACD $(4,22,3)$ model with optimal parameter values, not in the traditional MACD $(12,26,9)$ model. In Section 5.5, we have already confirmed that the three trading strategies did not improve the performance of the traditional model. Taking these findings into consideration, we can construct a hypothesis:

Hypothesis 1. Strategies to reduce false trade signals perform well for models with optimal parameter settings, but not for models with non-optimal parameter settings.

Yet the test results shown in the previous sections are just examples of models for which parameter settings are optimal, i.e., the $\operatorname{MACD}(4,22,3)$ model. We therefore extend our analysis to other good performance models to check the general result. More specifically, we are going to check whether models with good performance before applying any additional trading strategies improve on their original good results. Similar checks will also be performed on the poor performance models for robustness.

To accomplish this, we sort all of the examined 19,456 models in descending order of their returns over the whole period. Recall that we have examined these models to find optimal parameter settings in the first stage of this study, for which additional trading strategies to avoid false signals had not yet been applied. We define the top (bottom) 1000 ranked models as a representative group of models for which the parameter settings are optimal (non-optimal). It is for this reason that the difference in returns between the two opposite (top vs. bottom) groups is caused solely by the difference in the parameter settings. Now, the top (bottom) 1000 ranked models correspond to the approximately 5 percent best (worst) performing models among the 19,456 models. We next confirm what happens when we apply the three trading strategies discussed in the previous sections one-by-one to the top (bottom) 1000 ranked models. Table 11 reveals the results; it also includes results for an expansion of the number of models from the best (worst) 1000 to 2000.

Table 11. Results after Applying the Three Strategies to the Top and Bottom Ranked MACD Models.

\begin{tabular}{cccccccc}
\hline & & \multicolumn{2}{c}{ [A] Models that Produced Positive Returns } & \multicolumn{3}{c}{ [B] Models That Produced Increased Returns } \\
\cline { 3 - 7 } & & 1-Day & $\mathbf{3 0} \% \mathbf{1 0 d}$ & 1st-pkbm & 1-day & 30\%10d & 1st-pkbm \\
\hline \multirow{2}{*}{ Best } & 1000 & $998(99.8 \%)$ & $559(559 \%)$ & $898(89.8 \%)$ & $345(34.5 \%)$ & $111(11.1 \%)$ & $141(14.1 \%)$ \\
& 2000 & $1974(98.7 \%)$ & $1050(52.5 \%)$ & $1538(76.9 \%)$ & $592(29.6 \%)$ & $207(10.4 \%)$ & $282(14.1 \%)$ \\
\hline \multirow{2}{*}{ Worst } & 1000 & $0(0.0 \%)$ & $163(16.3 \%)$ & $1000(100.0 \%)$ & $0(0.0 \%)$ & $0(0.0 \%)$ & $120(12.0 \%)$ \\
& 2000 & $0(0.0 \%)$ & $383(19.2 \%)$ & $2000(100.0 \%)$ & $0(0.0 \%)$ & $1(0.1 \%)$ & $272(13.6 \%)$ \\
\hline
\end{tabular}

Note: Ranks of the smallest positive return in using the three additional strategy are 5942nd (1-day), 7761st (30\%10d) and 16,606th (1st-pkbm).

Before going into details, note that the returns of the top (bottom) 1000 and 2000 ranked models were all positive (negative) before applying any of the three strategies. As background information, consider that the rank of the smallest positive return was 5634th among the original 19,456 models.

Now look at the left-hand columns labeled '[A]'. These show how many models of the two opposite groups (top vs. bottom) were able to produce positive returns after applying the three strategies (1-day, $10 \% 10 \mathrm{~d}$, and 1st-pkbm) to the models. From the values in the column, we can see that there are many models that produced greater returns than the traditional MACD $(12,26,9)$ model at -4180 .

Look at the first sub-column labeled '1-day'. It shows that 99.8 percent of the top 1000 models and 98.7 percent of the top 2000 models maintained positive returns when we applied the 1-day minimum holding strategy, while all the models in the bottom 1000 and 2000 groups still produced negative returns without exception. These results show that almost all the models that have good parameter settings keep earning positive returns, 
while all of the models with bad parameter settings still experience negative returns without exception-which is almost perfectly consistent with our hypothesis stated above.

On the other hand, the second sub-column ' $30 \% 10 \mathrm{~d}$ ' shows that the aforementioned percentages of the two top groups fall by 55.9 percent and 52.5 percent, while the percentages of the two bottom groups rise to 16.3 percent and 19.2 percent. The third sub-column '1st-pkbm' shows that the aforementioned percentages of the two top groups were 89.8 percent and 76.9 percent, while the percentages for the two bottom groups were both 100 percent (i.e., the returns of all models in the two bottom groups turned positive from negative). These results show that even a model with optimal parameter settings risks reduced performance when an apparently good strategy to avoid false signals is applied —which is contrary to our hypothesis.

However, let us here assume that we have actual trades using the optimal sample $\operatorname{MACD}(4,22,3)$ model. Then, what matters here is not to secure a small positive return but rather to earn a significant return - at least greater than the return (9420) of our optimal sample model before considering strategies to avoid false signals.

The next columns labeled ' $[\mathrm{B}]$ ' in Table 11 show how many models of the two opposite (top and bottom) groups were able to produce greater returns, not only in terms of their original returns, but also by more than 9420 . Look at the first sub-column '1-day'. It reveals that 34.4 percent of the top 1000 and 29.6 percent of the top 2000 ranked models produced superior performance as stated above, while none of the two bottom 1000 and 2000 ranked models had good performance for the 1-day holding strategy. Almost the same observation can be made for the results presented in the next sub-column ' $30 \% 10 \mathrm{~d}$ '-these two results accord quite well with our hypothesis, especially for the models in the bottom ranked groups. However, the next sub-column '1st-pkbm' shows unexpected resultsthat 12.0 percent and 13.6 percent of the bottom 1000 and 2000 ranked models had good performance. This means that even though a model has non-optimal parameter settings, it has the potential to improve by adopting a good strategy to avoid false trade signals-quite contrary to our expectations.

However, what we can say with fair certainty is that the number of good performance models is far more in the top groups than the bottom groups. From this, we can see that it is more sensible to adopt a strategy to avoid false signals in models with optimal parameters than in models with non-optimal parameters.

Of course, we cannot ignore the possibility that an investor would adapt additional strategies to avoid false signals into an existing non-optimized MACD model. Such an investor might find it is useful in the end-as the results for the two bottom group models in the sub-column '1st-pkbm' show. Nevertheless, in a situation where the predictive power of the model was not good; it would be better to change the parameter settings of the existing model first, then later consider additional strategies to avoid false signals. If we take this perspective into account, the approach of improving a non-optimal model risks getting the priorities wrong. We therefore conclude our discussion in this section as follows: to avoid false signals caused by MACD rules, optimizing parameter settings to match the target market is most important. Applying additional strategies without improving the parameter settings must be of secondary importance.

\subsection{A Comparison with the Returns of the Buy-and-Hold Strategy}

There is one remaining issue: whether the optimal $\operatorname{MACD}(4,22,3)$ model with the three additional strategies outperforms the classic non-technical "buy-and-hold" investment strategy. This strategy has no concern for short-term fluctuations in the market nor any technical indicator. Therefore, this approach allows us to determine whether it makes sense to use the optimal MACD model even in a market that has a long-term increasing trend as illustrated in Figure 1. To test this, a monthly buy-and-hold analysis-which means simply buying Nikkei 225 stocks at the beginning of the month and then selling at the end of the month-has been performed over the 9 years. Below are the results. The reason why we 
consider the strategy on a monthly basis is to compare it fairly with the monthly returns of the MACD models in Section 5.6.

The first column titled ' $\mathrm{N}($ Trade)' in Table 12 indicates the number of trades. The next two columns ' $\mathrm{N}($ Return $>0)$ ' and ' $\mathrm{N}($ Return $<0)$ ' show the number of profitable and unprofitable trades, where the numbers inside the parentheses show the proportions of the trades that are profitable and unprofitable. 'Profit' and 'Loss' means the raw return of profitable and unprofitable trades; the 'Total' column shows the total of gains and losses. Compared to the preceding model's performance, this strategy has the potential for big gains but also lots of losses.

Table 13 reports the mean log returns obtained from using the buy-and-hold strategy and the preceding five MACD models (Note that the mean returns for '1-day, 30\%10d and 1st-pkbm' are the same values as those reported Tables 8-10). The values inside the parentheses show $t$-statistics for a test of the hypothesis that the buy-and-hold mean return is the same as the mean return for specific MACD model/strategy.

Table 12. The Performance of the Buy-and-hold Strategy.

\begin{tabular}{ccccccc}
\hline & N(Trade) & N(Return $>0)$ & N(Return < 0) & Profit & Loss & Total \\
\hline Whole Period & 108 & $64(0.593)$ & $44(0.407)$ & 40,150 & $-28,830$ & 11,320 \\
\hline $2011-2013$ & 36 & $21(0.583)$ & $15(0.417)$ & 11,940 & -6520 & 5420 \\
\hline $2014-2016$ & 36 & $24(0.667)$ & $12(0.333)$ & 14,680 & $-10,400$ & 4280 \\
\hline $2017-2019$ & 36 & $19(0.528)$ & $12(0.472)$ & 13,530 & $-11,910$ & 1620 \\
\hline
\end{tabular}

Table 13. $t$-test Comparisons of the Five MACD Models vs. the Buy-and-Hold Strategy.

\begin{tabular}{|c|c|c|c|c|c|c|}
\hline & Buy-and-Hold & 1-Day & $30 \% 10 d$ & 1st-pkbm & $\operatorname{MACD}(4,22,3)$ & $\begin{array}{l}\text { MACD } \\
(12,26,9)\end{array}$ \\
\hline Whole period & 0.0067 & $\begin{array}{l}0.01039 \\
(0.5418) \\
\end{array}$ & $\begin{array}{l}0.01190 \\
(0.7426) \\
\end{array}$ & $\begin{array}{l}0.00864 \\
(0.2566) \\
\end{array}$ & $\begin{array}{c}0.00449 \\
(-0.3261)\end{array}$ & $\begin{array}{l}-0.00195 \\
(-1.1963) \\
\end{array}$ \\
\hline 2011-2013 & 0.0113 & $\begin{array}{c}0.00923 \\
(-0.1519)\end{array}$ & $\begin{array}{c}0.00708 \\
(-0.3417)\end{array}$ & $\begin{array}{c}-0.01172 \\
(-1.601)\end{array}$ & $\begin{array}{c}0.00152 \\
(-0.7241)\end{array}$ & $\begin{array}{c}0.00302 \\
(-0.6005) \\
\end{array}$ \\
\hline 2014-2016 & 0.0067 & $\begin{array}{l}0.00701 \\
(0.0293) \\
\end{array}$ & $\begin{array}{l}0.01416 \\
(0.5346) \\
\end{array}$ & $\begin{array}{c}0.02594 \\
(1.4788) * \mathrm{c}\end{array}$ & $\begin{array}{c}0.00437 \\
(-0.2018)\end{array}$ & $\begin{array}{l}-0.00713 \\
(-1.0463) \\
\end{array}$ \\
\hline 2017-2019 & 0.0021 & $\begin{array}{c}0.01492 \\
(1.2872) * a\end{array}$ & $\begin{array}{c}0.01445 \\
(1.2533) * b\end{array}$ & $\begin{array}{l}0.01170 \\
(0.8634)\end{array}$ & $\begin{array}{l}0.00758 \\
(0.5249)\end{array}$ & $\begin{array}{c}-0.0175 \\
(-0.3648)\end{array}$ \\
\hline
\end{tabular}

$p$-value: ${ }^{\mathrm{a}}=0.1011,{ }^{\mathrm{b}}=0.1071,{ }^{\mathrm{c}}=0.0718{ }^{*}$ show statistical significance at the 10 percent levels of confidence for one-tailed tests.

Look first at the column titled 'Buy-and-hold'. It shows that trading using the buyand-hold strategy leads to profits for the whole period with monthly returns of 0.67 percent on average. Profits of the three sub-periods are 1.13, 0.67 and 0.21 percent, respectively. As for the highest performing return in the first sub-period (i.e., 1.13\%), we can interpret from Figure 1 that it resulted almost exclusively from the clear uptrend during the year 2013. It makes the return of the buy-and hold strategy for the first sub-period outperform the other five models. We can confirm this again in Figure 3.

However, interestingly for the second and third sub-periods and the whole period, the returns of the MACD $(4,22,3)$ model with each of the three strategies (1-day, 30\%10d and 1st-pkbm) are higher than that of the buy-and-hold strategy. As for the third sub-period, the returns for the model with the '1-day' and ' $30 \% 10 \mathrm{~d}$ ' strategies are statistically significant at an almost 10 percent level. As for the second sub-period, the return for the model with the '1st-pkbm' strategy is also statistically significant at the 10 percent level. Judging from the mean return of the whole period, the $\operatorname{MACD}(4,22,3)$ model with each of the three strategies outperforms the buy-and-hold strategy. At the same time, we can see that the former 
performs far better in a volatile bull market (such as 2014-2019 as shown in Figure 1) than a trendless, sideways market (such as 2011-2012).

Taking these findings into consideration, we can say that: If an additional strategy to avoid false signals is applied to a MACD model with optimal parameter settings, it can deliver better performance than a buy-and-hold strategy-even in a long-term clear uptrend market where a buy-and-hold strategy has the potential to deliver better performance than a technical indicator. Figure 3 shows this insight in a different way: it is for the year 2013 where the index rose sharply that the buy-and-hold strategy shows its relative strength.
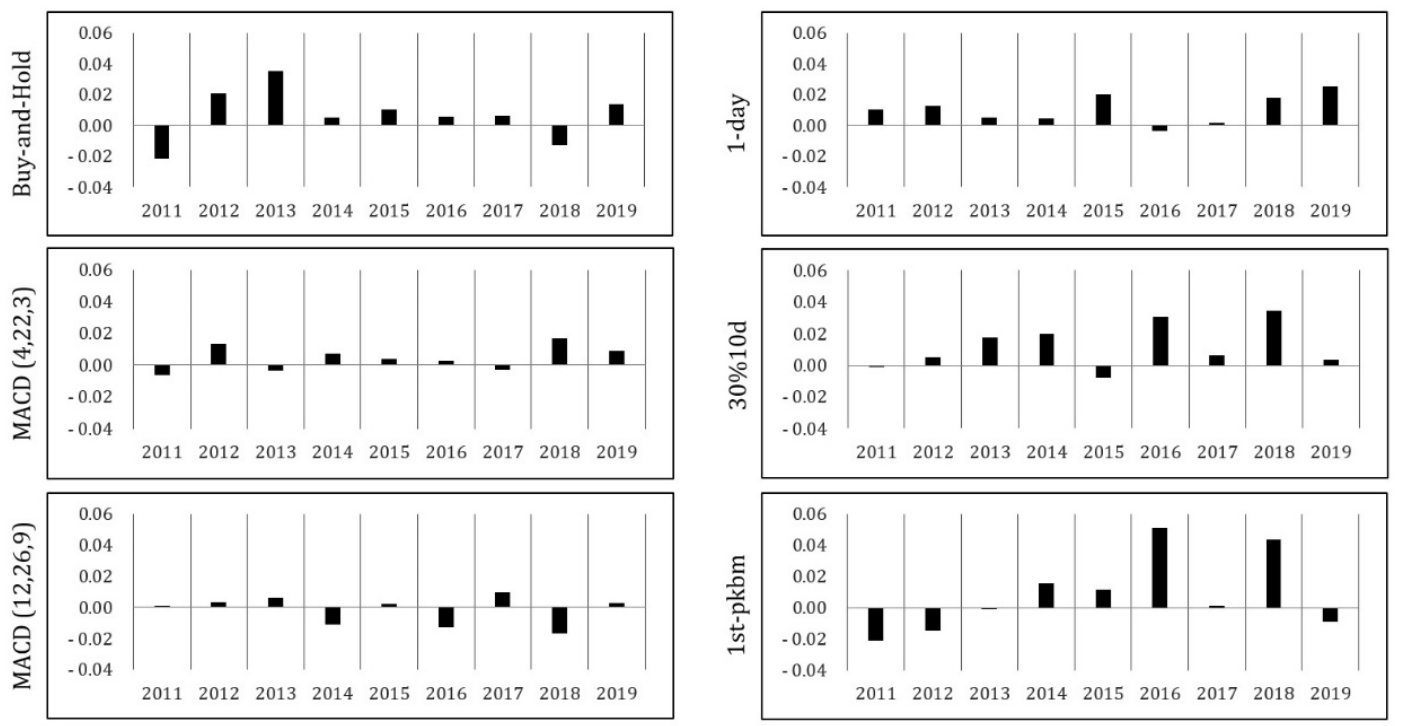

Figure 3. The Yearly Changes in Mean Log Returns of All Models. Note: The length of each bar indicates yearly mean log returns that are calculated from the log returns for every transaction in the year.

\section{Concluding Remarks and Summary}

This paper examined the three questions stated in the first section and found:

(1) The application of the traditional MACD $(12,26,9)$ model to the Japanese stock market led to a disappointing large negative return over the period from 2011 to 2019, while many other models with different parameter values delivered higher positive returns (see Table 1).

(2) Substituting more-optimized, better-fitted parameter values $(4,22,3)$ for the traditional $(12,26,9)$ values as an example, produced much higher positive returns over the whole period than the traditional model (see Table 2).

(3) Applying the three modified trading strategies (1-day, 10\%10d and 1st-pkbm) in addition to the example MACD $(4,22,3)$ model with the optimized parameter values was effective in reducing false trade signals and enhanced profitability (see Tables 3-5). Yet, the three strategies did not improve the performance of the traditional model. Indeed, none of the three strategies turned the negative performance of the traditional model into positive performance (see Table 6). And, to be more specific:

- $\quad$ Each of the three additional trading strategies applied to the example model with the more-optimized parameter values $(4,22,3)$ produced significantly higher returns compared to the traditional model (over the whole period, see Tables 8-10) and even compared to the simple buy-and-hold strategy (for the second or third sub-period, see Table 13).

- When extended to the top (bottom) 1000 and 2000 ranked models of the 19,546 MACD simulated models-which included non-optimized parameters-the number of good performance models was far greater for the top ranked groups (see Table 11). High ranked models had their original good performance improve to be even better after applying the strategies to reduce false trade signals. Lower 
ranked models did not experience much of an improvement from the strategies (see Table 11). However, there is evidence that even poor performing models can in some cases be improved by applying an apparently superior false signal rejection strategy as was the case for '1st-pkbm' approach.

To sum up the results obtained by this study, we can make two conclusions:

(1) Applying the MACD indicator to the Japanese stock market can earn significant positive returns for investors if they use optimal values for the three parameters of the MACD momentum indicator.

(2) Optimizing the three parameter values should take precedence before searching for supplementary trade strategies to avoid false signals.

The first concluding remark suggests that the Nikkei 225 Futures market is not weakform efficient in the sense that the market does not incorporate all public information. This finding is consistent with the work of Anghel (2015). He assessed the state of information efficiency of the stock markets of 75 countries (1268 companies) over the period from 2001 to 2012 by using two MACD-based trading rules. According to his ranking of the relative market efficiency, Japan and the United States are ranked in the 56th and 59th positions respectively, and both belonged to a group of 34 countries where it is possible to obtain abnormal profits by using one of the two MACD trading rules.

The second concluding remark argues that parameters of the MACD should be optimized. This is consistent with Borowski and Pruchnicka-Grabias (2019). They investigated optimal parameter values of the MACD indicator for 140 companies listed on the Warsaw Stock Exchange using data from 2000 to 2018. They searched for each company's ideal parameter values to maximize returns. Although some companies had identical optimal parameters, many were different. They concluded, " ... investors should not follow them — the traditional parameter values $(12,26,9)$ - automatically, but rather look for optimal values for each market and each company". (p. 457) This is similar to the argument of this research: the three parameter values should be determined through a more-optimized and systematic approach tailored to each financial market because effective signals of the MACD momentum indicator will depend on these values. However, their research diverged to consider the regularity of the optimal parameter values and whether each value of the optimal three parameters was an even or an odd number. As a result, they discovered that the highest performances were obtained for "odd-even-odd" combinations of the three parameters.

In contrast to their result, this research is focused on the issue whether additional strategies make it possible to improve MACD models by avoiding false signals; in other words, to analyze the effects of applying additional strategies to the optimized and nonoptimized parameter settings. The reason why this issue is crucial to practitioners is that they are seeking and often using additional trading strategies to modify the trade signals generated by their models when the predictive power of their models degrades. From this point of view, this research is innovative in the sense that it finds an answer for practitioners - this is a highlight of this study. To add a remark in passing on the study by Borowski and Pruchnicka-Grabias (2019), they examined models, including irrational models, where the value of the short-term parameter was greater than or equal to the value of long-term parameter. In this respect, the approach of this research is more rational and systematic - this point is a contribution to the literature.

Even when traders use optimized parameter values, they will still be troubled by false trade signals. This is an inherit limitation of the MACD indicator as well as for other technical analysis tools. This means that traders must devise strategies to improve trade signal quality. For this reason, this research explored ways to limit false signals, even in the context of non-optimized models. To the best knowledge of the author, this issue has not been previously discussed in the literature. Therefore, this research advises traders who use the MACD tool that: 
- The three parameters of the MACD model should be changed to fit each market. Optimizing the parameters of the MACD model and revising existing trading strategies should be done constantly in order to exploit market inefficiencies.

- When the predictive power of an existing trading model degrades, traders should prioritize the re-optimization of the parameter values of the model rather than search for additional trading strategies to modify the trade signals generated by the model. Such an approach is both prudent and far more efficient than searching for strategies at random without the benefit of parameter optimization.

It is also useful information for practitioners to know that the traditional MACD model parameters are not optimal. Regarding the best time to revise the parameter values and additional trading strategies, research by Menkhoff (2010) is helpful. He surveyed 692 fund managers in five countries and found that they do not like to keep using the same trading strategy for long periods of time and attempt to adjust their trading strategies to the latest market conditions. According to the results of his survey, 90.4 percent of them have horizons that range from a few days up to 6 months.

As for the method to best select parameter values, one approach might be to use complex optimization algorithms such as genetic algorithms or neural networks and the other is improving the existing methodology. ${ }^{2}$ However, before employing these alternative optimization approaches, algorithms, it must be noted that there is room to improve the existing methodology. It is especially important to consider the historical volatility of stock price movements. In the author's opinion, future research should prioritize building and testing new models with self-diagnostic functions capable of revising existing trading strategies and optimizing the parameters of the MACD model at regular intervals or irregularly when a structural shift in the market takes place.

Finally, let us add a brief comment about the policy implications of the research. This research reports that the Japanese market is not weak-form efficient. The evidence for this is the good out-of-sample performance. This suggests that policy makers and regulators might intervene when markets are not efficient or not rational.

Funding: The APC was funded by Nanzan University.

Data Availability Statement: Data was obtained from an official data provider, JPX Data Cloud and are available from http:/ / db-ec.jpx.co.jp with the permission of the provider.

Acknowledgments: The author would like to acknowledge his colleague Marc Bremer for his proofreading and valuable comments. The author is indebted to Masayuki Arakawa for his assistance in constructing the trading simulation system used in this study and detailed checking of the results. The author appreciates the valuable suggestions of the two anonymous reviewers.

Conflicts of Interest: The author declares no conflict of interest. Nanzan University had no role in the design of the study; in the collection, analyses, or interpretation of data; in the writing of the manuscript, and in the decision to publish the results.

\section{References}

Abbey, Boris, and John. Doukas. 2012. Is Technical Analysis Profitable for Individual Currency Traders? Journal of Portfolio Management 39: 142-50. Available online: https:/ / efmaefm.org/0DOUKAS/publications/pdf/IsTechnicalAnalysisProfitable_12-14-2011.pdf (accessed on 10 September 2020). [CrossRef]

Anghel, Gabriel Dan. 2015. Stock Market Efficiency and the MACD. Evidence from Countries around the World. Procedia Economics and Finance 32: 1414-31. [CrossRef]

Appel, Gerald. 1979. The Moving Average Convergence Divergence Trading Method. Great Neck: Signalert Corp.

Armour, Joseph, Melissa Lofton, Olamide Oyenekan, and Massoud Metghalchi. 2010. Efficient Market Hypothesis and Technical Analysis: The Irish Stock Index. In International Handbook of Academic Research and Teaching 71. Berlin/Heidelberg: Springer.

2 There are many potential approaches to select optimal parameter values. These include the approaches used by Wiles and Enke (2015); Wang et al. (2011); Wang and Kim (2018) and Mitsui (2014). 
Borowski, Krzysztof, and Izabela Pruchnicka-Grabias. 2019. Optimal Lengths of Moving Averages for the MACD Oscillator for Companies Listed on the Warsaw Stock Exchange. Bank i Kredyt (National Bank of Poland) 50: 457-78. Available online: https://www.researchgate.net/publication/337245247_Optimal_lengths_of_moving_averages_for_the_MACD_oscillator_ for_companies_listed_on_the_Warsaw_Stock_Exchange (accessed on 2 December 2020).

Chen, Chien-Ping, and Massoud Metghalchi. 2012. Weak-Form Market Efficiency: Evidence from the Brazilian Stock Market. International Journal of Economics and Finance 4: 22-32. [CrossRef]

Chong, Terence Tai-Leung, and Wing-Kam Ng. 2008. Technical Analysis and the London Stock Exchange: Testing the MACD and RSI Rules using the FT30. Applied Economics Letters 15: 1111-14. [CrossRef]

Chong, Terence Tai-Leung, Wing-Kam Ng, and Venus Khim-Sen Liew. 2014. Revisiting the Performance of MACD and RSI Oscillators. Journal of Risk and Financial Management 7: 1-12. [CrossRef]

Du Plessis, Anton Wouter. 2013. The Effectiveness of a Technical Analysis Strategy versus a Buy-and-hold Strategy on the FTSE/JSE Top 40 Index Shares of the JSE Ltd: The Case of the Moving Average Convergence Divergence Indicator. Ph.D. dissertation, University of Johannesburg, Johannesburg, South Africa. Available online: https://ujcontent.uj.ac.za/vital/access/manager/Repository/uj: 7550? site_name=GlobalView (accessed on 12 August 2020).

Fama, Eugene. 1970. Efficient Capital Markets: A Review of Theory and Empirical Work. The Journal of Finance 25: 383-417. [CrossRef]

Hejase, Ale, Srour Ruba, Hejase Hussin, and Joumana Younis. 2017. Technical Analysis: Exploring MACD in the Lebanese Stock Market. Journal of Research in Business, Economics and Management 8: 1493-502. Available online: http://scitecresearch.com/ journals/index.php/jrbem/article/view/1077 (accessed on 10 August 2020).

Meissner, Gunter, Albin Alex, and Kai Nolte. 2001. A Refined MACD Indicator-Evidence against the Random Walk Hypothesis? ABAC Journal 21: 1-17. Available online: http:/ / www.abacjournal.au.edu/2001/may01/refined.pdf (accessed on 12 September 2020).

Menkhoff, Lukas. 2010. The Use of Technical Analysis by Fund Managers: International Evidence. Journal of Banking E Finance 34: 2573-86. [CrossRef]

Mitsui, Hidetoshi. 2014. Bull and Bear Market Analysis of the Nikkei 225 Futures and TOPIX Futures. Keizai Shushi (The Nihon University Economic Review) 84: 19-39. Available online: http://www.eco.nihon-u.ac.jp/about/magazine/shushi/pdf/84_01/84_1_04.pdf (accessed on 10 September 2020).

Murphy, John. 1999. Technical Analysis of the Financial Markets. New York: Prentice Hall Press, ISBN 978-0735200661.

Nor, Safwan Mohd, and Guneratne Wickremasinghe. 2014. The Profitability of MACD and RSI Trading Rules in the Australian stock Market. Investment Management and Financial Innovations 11: 194-99. Available online: https://www.researchgate.net/ publication/272238241_The_profitability_of_MACD_and_RSI_trading_rules_in_the_Australian_stock_market (accessed on 12 August 2020).

Pring, Martin. 2002. Momentum Explained. New York: McGraw-Hill, vols. 1-2, ISBN 978-0071384025/978-0071384032.

Rosillo, Rafael, David de la Fuente, and Jose Brugos. 2013. Technical Analysis and the Spanish Stock Exchange: Testing the RSI, MACD, Momentum and Stochastic Rules using Spanish Market Companies. Applied Economics 45: 1541-50. [CrossRef]

Wang, Jian, and Junseok Kim. 2018. Predicting Stock Price Trends using MACD Optimized by Historical Volatility. Mathematical Problems in Engineering 2018: 1-12. [CrossRef]

Wang, Jian-Zhou, Ju-Jie Wang, Zhe-George Zhang, and Shu-Po Guo. 2011. Forecasting Stock Indices with Back Propagation Neural Networks. Expert Systems with Applications 38: 14346-55. [CrossRef]

Wiles, Phoebe, and David Enke. 2015. Optimizing MACD Parameters via Genetic Algorithms for Soybean Futures. Procedia Computer Science 61: 85-91. [CrossRef] 